www.jmscr.igmpublication.org

Impact Factor (SJIF): 6.379

Index Copernicus Value: 79.54

ISSN (e)-2347-176x ISSN (p) 2455-0450

crossrefDOI: https://dx.doi.org/10.18535/jmscr/v6i12.15

Journal Of Medical Science And Clinical Research

\title{
Single Institutional Comparative Study of Short versus Long Course Radiotherapy for Palliation of Painful Bone Metastasis
}

\author{
Authors \\ Laxmi Singotia ${ }^{1}$, Sanandan Patel $^{2}$, A. K. Saxena ${ }^{3}$, Shyamji Rawat ${ }^{4}$, Rajesh Jain ${ }^{5}$ \\ Lalit Patel $^{6}$ \\ 1,2,3,4,5 Dept. of Radiotherapy, NSCB Medical College, Jabalpur, M.P. India \\ Corresponding Author \\ Dr. Sanandan Patel \\ Email: sanandan.patel@gmail.com
}

\section{Abstract}

Purpose: External beam radiotherapy is an effective treatment for symptomatic bone metastases. This study aims to compare the $8 G y$ in single fraction and 30Gy in 10 fractions radiotherapy for palliation of bone metastases in terms of pain relieving efficacy, toxicity and feasibility of different dose schedules.

Material and Method: In this two arm, prospective comparative study we enrolled 60 patients of $\geq 18$ years with $K P S \geq 40$, histologically proven malignancy with radiologically confirmed, painful bone metastases and randomized (1:1) to receive either $8 \mathrm{~Gy}$ in a single fraction or $30 \mathrm{~Gy}$ in 10 fractions with Zoledronic acid every 4 weeks for 6 months. Treatment response was determined by Brief Pain Inventory and toxicity assessment was done by CTCAE version 4.03.

Results: Overall response was $76.6 \%$ in both groups. In $8 G y$ group complete response and partial response were $36.7 \%$ and $40 \%$ respectively compared with $30 \%$ and $46.7 \%$ in 30 Gy group respectively (p =0.76). In both arms frequently reported toxicities were anorexia and anemia. No grade 4-5 toxicity were reported in any patient. Retreatment rate were higher in 8 Gy group than 30 Gy group $(10 \%$ vs 3.3\%, $p=$ 0.61 ).

Conclusion: $8 G y / 1$ fraction is as effective as 30Gy/10 fraction for palliation of painful bone metastasis with less side effects and more feasible for patients and caregivers in terms of treatment duration, cost and hospital visit.

Keywords: Painful bone metastasis, Zoledronic acid, radiotherapy, single fraction.

\section{Introduction}

The exact incidence of bone metastases is difficult to determine, but estimates are that $>100,000$ people in the United States will develop osseous metastatic disease annually ${ }^{[1],[2]}$. Prostate, breast, and lung cancers are the most common malignancies in adults and are the most common tumours that metastasize to bone ${ }^{[3]}$.
Bone metastases are the most common cause of cancer-related pain ${ }^{[4]}$. The treatment of pain from bone metastases involves the use of multiple complementary approaches including radiotherapy, surgery, chemotherapy, bisphosphonates, calcitonin, and analgesics ${ }^{[5]}$.

External beam radiotherapy has been reported to be effective in palliating painful bone metastases, with 
partial pain relief seen in $80 \%$ to $90 \%$ of patients and complete pain relief in $50 \%$ of patients. Patients who have improvement in pain after radiotherapy may also have improvement in emotional functioning, decreased insomnia and decreased constipation, and overall improvement in quality-oflife scores ${ }^{[6]}$.

There have been multiple randomized, prospective trials in the last 30 years comparing shorter-course, lower-total-dose treatment to the more - standard longer-course, higher-dose treatment and concluded that Single-dose treatments of 8 Gy provide similar pain relief to longer-treatment regimens (30 Gy in 10 fractions or 20 to $24 \mathrm{~Gy}$ in five to eight treatments $)^{[6]}$. Despite these results, longer courses of treatment to higher total doses of radiation remain the most commonly used schedules in the United States, typically with a regimen of 30 Gy given in 10 treatment fractions over 2 weeks ${ }^{[7]}$.

The use of shorter course of radiation therapy in palliation of symptomatic bone metastases makes it easier for patients and their caregiver to arrange logistics of therapy. One or 2 visits to treatment facility for planning and treatment save time and resources for patients, caregivers and health care providers compared to $\geq 10$ visits.

This study aims to compare the $8 \mathrm{~Gy}$ single fraction and 30Gy in 10 fractions radiotherapy concurrently with zoledronic acid for palliation of bone metastases in terms of pain relieving efficacy, toxicity and feasibility of different dose schedules.

\section{Aims \& Objectives}

The purpose of the study is to compare the single fraction radiotherapy and multiple fraction radiotherapy for palliation of radiologically proven bone metastases from solid tumour in terms of:-

$>$ Pain relieving efficacy

$>$ Toxicity

$>$ Feasibility of different dose schedules

\section{Material and Method}

This is a single centre, prospective, observational, randomized non-blinded study in which 60 patients of painful bone metastasis were randomized (1:1) to receive either 8 Gy in single fraction on 1 day or 30 Gy in 10 fractions over 2 weeks with Zoledronic acid every 4 weeks for 6 months. All the patients were treated on a telecobalt machine with twodimensional radiation planning. The inclusion criteria's were age $\geq 18$ years, histologically proven malignancy with radiologically proven bone metastases, KPS $\geq 40$, worst pain score from BPI $\geq$ 5 and a signed study specific informed consent given by the patient before randomization. Prior radiation therapy or palliative surgery for same bone metastases, pathological fracture or impending fracture of treatment site, clinical or radiological evidence of spinal cord or cauda equine compression, KPS $<40$ and pregnancy or lactation were exclusion criteria for this study. The response to radiotherapy was assessed by BPI questionnaires at 15th and 30th day of start of radiation then monthly up to 6 month Treatment related toxicity assessed by CTCAE version 4.03 during and after radiation therapy at follow up visits. Treatment response is categorized (on worst pain score from brief pain inventory) as follows:- 1)Complete response $-\mathrm{A}$ post treatment score of 0 ; 2)Partial response-A post treatment improvement of pain score $\geq 2$ points; 3)Stable response $-\mathrm{A}$ post treatment pain score within1 point of initial pain score; 4) Progressive disease -A post treatment increase of pain score $\geq 2$ points.

\section{Statistics}

Statistical analysis was performed with software (SPSS, version 20). Descriptive statistics were used to express the data findings. For categorical variables, Chi square or Fischer exact test was used as appropriate. $\mathrm{P}$ values $\leq 0.05$ was considered statistically significant.

\section{Results}

From 2015 to 2017, 60 patients with painful bone metastases were randomized for the trial, 30 patients to a single fraction and 30 patients to 10 fractions of palliative radiotherapy. Of these patients $50 \%$ were male and 50\% were female. Age range was 33-84 years (mean -54.2 years). Majority of the patients 
were of KPS between 40 and 70(96.7\%). Most common primary tumour was carcinoma breast (33.3\%) followed by carcinoma lung (18.3\%), carcinoma prostate $(18.3 \%)$, carcinoma cervix $(5.0 \%)$, carcinoma gall bladder $(5.0 \%)$, carcinoma thyroid (5.0\%), head and neck cancer (5.0\%), colorectal cancer $(3.3 \%)$ and unknown primary (3.3\%). A single patient of carcinoma esophagus $(1.7 \%)$ and carcinoma pancreas $(1.7 \%)$ were also included in this trial. Patients with variable sites of bone metastasis were included in this study. Most common site being vertebrae $(47.5 \%)$, lumbar (36 patients- $17.48 \%$ ) followed by thoracic (33 patients $-16 \%$ ), cervical (15 patients $-17.28 \%$ ) and sacrum (14 patients- 6.8\%). Other non-vertebral sites were pelvic bones (29 patients $-14.08 \%$ ), ribs (18 patients $-8.74 \%$ ), femur (16 patients $-7.77 \%$ ), humerus (11 patients $-5.34 \%)$, scapula (10 patients - 4.85\%), clavicle (5 patients $2.43 \%$ ), skull (5 patients $2.43 \%$ ), tibia ( 2 patients $-0.97 \%$ ) and fibula, radius and ulna ( 1 patient $-0.5 \%$ to each site). The baseline characteristics of both group patients are summarized in Table 1.

The overall response rate to palliative RT in our study was $76.6 \%$, which was similar in both groups. In single fraction group complete response rate and partial response rate were $36.7 \%$ and $40 \%$ respectively whereas $20 \%$ and $3.3 \%$ patients showed stable response and progressive disease respectively. In multiple fraction group complete response rate and partial response rate were $30 \%$ and $46.7 \%$ respectively whereas $23.3 \%$ patients showed stable response (Table 2).

In our study both group patients experienced same toxicity profile. Most common toxicity was anorexia followed by anemia, nausea, vomiting, diarrhoea, leucopenia and thrombocytopenia. Grade 1 toxicity was $20.4 \%$ ( $18.5 \%$ vs $22.9 \%$ ), grade 2 toxicity was $27.8 \%(26.2 \%$ vs $29.5 \%)$ and grade 3 toxicity was $8.8 \%$ (9.0\% vs $8.5 \%)$. No grade $4-5$ toxicity was experienced by patients during study. No incidence of radiation induced myelopathy or pathological fracture was noted during study period (Table 3).
Reirradiation rate was $10 \%(\mathrm{n}=3)$ in $8 \mathrm{~Gy}$ group and $3.3 \%(\mathrm{n}=1)$ in $30 \mathrm{~Gy}$ in 10 fractions group (difference $=6.7 \%, p=0.30$ ) within 6 months of follow up.

In single fraction group, patients completed their treatment in 30 days (on average 1day/patient) where as in multiple fraction group; patients completed their treatment in 450 days (on avarage15 days/patient). Thus multiple fraction group patients needed on average 14 additional days to complete treatment.

Table 1 Pre-treatment characteristics of eligible patients

\begin{tabular}{|c|c|c|c|c|}
\hline \multicolumn{2}{|c|}{ Characteristics } & \multirow{2}{*}{$\begin{array}{c}8 \mathrm{~Gy} / 1 \# \\
\begin{array}{c}\text { group } \\
(\mathrm{n}=30)\end{array} \\
54.9\end{array}$} & \multirow{2}{*}{$\begin{array}{c}30 \\
\begin{array}{c}\text { Gy/10\# } \\
\text { group } \\
(\mathrm{n}=30)\end{array} \\
53.5\end{array}$} & \multirow{2}{*}{$\begin{array}{l}\text { Total } \\
\\
54.2 \\
\end{array}$} \\
\hline Age, years & Mean & & & \\
\hline & Median & 53.5 & 50 & 51.5 \\
\hline & Range & $33-84$ & $34-82$ & $33-84$ \\
\hline \multirow[t]{2}{*}{$\operatorname{Sex}(\%)$} & Male & $16(53.3)$ & $14(46.7)$ & $30(50)$ \\
\hline & Female & $14(46.7)$ & $16(53.3)$ & $30(50)$ \\
\hline \multirow[t]{5}{*}{ KPS (\%) } & 80 & $1(3.3)$ & $0(0)$ & $1(3.3)$ \\
\hline & 70 & $3(10)$ & $1(3.3)$ & $4(13.3)$ \\
\hline & 60 & $11(36.7)$ & $12(40.0)$ & $23(38.3)$ \\
\hline & 50 & $10(33.3)$ & $13(43.3)$ & $23(38.3)$ \\
\hline & 40 & $5(16.7)$ & $4(13.3)$ & $9(15)$ \\
\hline \multirow{11}{*}{$\begin{array}{l}\text { Primary } \\
\text { cancer site } \\
(\%)\end{array}$} & Breast & $9(30)$ & $11(36.6)$ & $20(33.3)$ \\
\hline & Prostate & $4(13.3)$ & $7(23.3)$ & $11(18.3)$ \\
\hline & Lung & $5(16.7)$ & $6(20)$ & $11(18.3)$ \\
\hline & Cervix & $3(10)$ & $0(0)$ & $3(5.0)$ \\
\hline & $\begin{array}{l}\text { Gall } \\
\text { bladder }\end{array}$ & $2(6.6)$ & $1(3.3)$ & $3(5)$ \\
\hline & Thyroid & $2(6.6)$ & $1(3.3)$ & $3(5)$ \\
\hline & $\begin{array}{l}\text { Head and } \\
\text { neck }\end{array}$ & $2(6.6)$ & $1(3.3)$ & $3(5)$ \\
\hline & Colorectal & $2(6.6)$ & $0(0)$ & $2(3.3)$ \\
\hline & Esophagus & $0(0)$ & $1(3.3)$ & $1(1.7)$ \\
\hline & Pancreas & $0(0)$ & $1(3.3)$ & $1(1.7)$ \\
\hline & $\begin{array}{l}\text { Unknown } \\
\text { primary }\end{array}$ & $1(3.3)$ & $1(3.3)$ & $2(3.3)$ \\
\hline \multirow{6}{*}{$\begin{array}{l}\text { Site of } \\
\text { bone } \\
\text { metastases } \\
(\%)\end{array}$} & $\begin{array}{l}\text { Cervical } \\
\text { vertebrae }\end{array}$ & $5(5)$ & $10(9.3)$ & $15(7.2)$ \\
\hline & $\begin{array}{l}\text { Thoracic } \\
\text { vertebrae }\end{array}$ & $17(17)$ & $16(14.9)$ & $33(16)$ \\
\hline & $\begin{array}{l}\text { Lumbar } \\
\text { vertebrae }\end{array}$ & $19(19)$ & $17(15.8)$ & $36(17.4)$ \\
\hline & Sacrum & $6(6)$ & $8(7.4)$ & $14(6.7)$ \\
\hline & $\begin{array}{l}\text { Pelvic } \\
\text { bones }\end{array}$ & $12(12)$ & $17(15.8)$ & $29(14)$ \\
\hline & Other & $40(40)$ & $39(36.4)$ & $79(38.1)$ \\
\hline \multirow{2}{*}{$\begin{array}{l}\text { Worst pain } \\
\text { score on } \\
\text { BPI }\end{array}$} & $5-6$ & $8(26.6)$ & $6(20)$ & $14(23.3)$ \\
\hline & $7-10$ & $22(73.3)$ & $24(80)$ & $46(76.6)$ \\
\hline
\end{tabular}


Table 2: Response to treatment, as measured by BPI worst pain score

\begin{tabular}{|l|c|c|c|}
\hline Response & $\begin{array}{c}8 \text { Gy/1\# group } \\
(\mathrm{n}=30)\end{array}$ & $\begin{array}{c}30 \mathrm{~Gy} / 10 \# \\
\text { group }(\mathrm{n}=30)\end{array}$ & \multirow{2}{*}{ P value } \\
\hline Complete & $11(36.7)$ & $9(30.0)$ & \multirow{2}{*}{0.698} \\
\hline Partial & $12(40.0)$ & $14(46.7)$ & \\
\hline Stable & $6(20.0)$ & $7(23.3)$ & \\
\cline { 1 - 3 } $\begin{array}{l}\text { Progressive } \\
\text { disease }\end{array}$ & $1(3.3)$ & $0(0.0)$ & \\
\hline
\end{tabular}

Table 3: Toxicity of treatment

\begin{tabular}{|c|c|c|c|}
\hline Adverse events & $\begin{array}{c}\text { Toxicity } \\
\text { grade }\end{array}$ & $\begin{array}{c}8 \mathrm{~Gy} / 1 \# \\
\text { group } \\
(\mathrm{n}=30)\end{array}$ & $\begin{array}{c}30 \mathrm{~Gy} / 10 \# \\
\text { group } \\
(\mathrm{n}=30)\end{array}$ \\
\hline \multirow[t]{4}{*}{ Anemia (\%) } & Grade 1 & $5(16.6)$ & $1(3.3)$ \\
\hline & Grade 2 & $9(30)$ & $16(53.3)$ \\
\hline & Grade 3 & $12(40)$ & $11(36.7)$ \\
\hline & Grade 4 & $0(0)$ & $0(0)$ \\
\hline \multirow[t]{4}{*}{ Leucopenia (\%) } & Grade 1 & $7(23.3)$ & $9(30)$ \\
\hline & Grade 2 & $1(3.3)$ & $2(6.6)$ \\
\hline & Grade 3 & $0(0)$ & $0(0)$ \\
\hline & Grade 4 & $0(0)$ & $0(0)$ \\
\hline \multirow{4}{*}{$\begin{array}{l}\text { Thrombocytopenia } \\
(\%)\end{array}$} & Grade 1 & $2(6.6)$ & $1(3.3)$ \\
\hline & Grade 2 & $0(0)$ & $0(0)$ \\
\hline & Grade 3 & $0(0)$ & $0(0)$ \\
\hline & Grade 4 & $0(0)$ & $0(0)$ \\
\hline \multirow[t]{4}{*}{ Nausea (\%) } & Grade 1 & $7(23.3)$ & $10(33.3)$ \\
\hline & Grade 2 & $9(30)$ & $12(40)$ \\
\hline & Grade 3 & $1(3.3)$ & $3(10)$ \\
\hline & Grade 4 & $0(0)$ & $0(0)$ \\
\hline \multirow[t]{4}{*}{ Vomiting (\%) } & Grade 1 & $9(30)$ & $11(36.6)$ \\
\hline & Grade 2 & $4(13.3)$ & $7(23.3)$ \\
\hline & Grade 3 & $1(3.3)$ & $1(3.3)$ \\
\hline & Grade 4 & $0(0)$ & $0(0)$ \\
\hline \multirow[t]{4}{*}{ Anorexia (\%) } & Grade 1 & $5(16.6)$ & $10(33.3)$ \\
\hline & Grade 2 & $18(60)$ & $18(60)$ \\
\hline & Grade 3 & $4(13.3)$ & $2(6.6)$ \\
\hline & Grade 4 & $0(0)$ & $0(0)$ \\
\hline \multirow[t]{4}{*}{ Diarrhoea (\%) } & Grade 1 & $4(13.3)$ & $5(16.6)$ \\
\hline & Grade 2 & $14(46.6)$ & $7(23.3)$ \\
\hline & Grade 3 & $1(3.3)$ & $1(3.3)$ \\
\hline & Grade 4 & $0(0)$ & $0(0)$ \\
\hline
\end{tabular}

\section{Discussion}

In this study most common primary diagnosis with bone metastases was Breast cancer (33.3\%) followed by ca lung (18.3\%) and ca prostate (18.3\%). According to Coleman RE (2004) ${ }^{\text {[8] }}$ prevalence of metastatic bone disease is highest in breast and prostate cancer, with both together accounting for $80 \%$ of all cases. One other study conducted by Body JJ (1992) ${ }^{[9]}$, the most common bone metastasizing tumour were breast cancer $(47 \%$ to $85 \%$ ), prostate cancer ( $33 \%$ to $85 \%$ ) and lung cancer $(32 \%$ to $60 \%)$. The reason for lower incidence of breast cancer, prostate cancer and lung cancer in our study may accounted for the small sample size in our study, increased incidence of these diseases in developed countries on account of their better socioeconomic status and longer life expectancy.

The overall response rate in this study was $76.6 \%$, which was similar in both groups. These results are equivalent to the results reported in the international literatures. In the Dutch Bone Metastases Study the overall response rate was $71 \%^{[10]}$. In the Bone Pain Trial Working Party Report ${ }^{[11]} 78 \%$ of patients experienced some degree of pain relief. In RTOG 97-14 trial ${ }^{[7]}$ the overall response rate was $66 \%$. In an updated meta-analysis reporting 25 randomized trials by Chow $\mathrm{E}$ et. al revealed the overall and complete response rates were $60 \%$ and $23 \%$ respectively in single-fraction arm versus, $61 \%$ and $24 \%$ respectively in multiple-fraction arm, again demonstrating equal efficacy ${ }^{[12]}$.

Complete response rate achieved in our study was $33.3 \%$ and partial response rate was $43.3 \%$ which is also equivalent to the Dutch Bone Metastases Study [10] (complete response rate 35\%) and systemic review by Sze et al ${ }^{[13]}$ (complete response rate 32\%$34 \%)$.

In single fraction group complete response rate and partial response rate were $36.7 \%$ and $40 \%$ respectively whereas $20 \%$ and $3.3 \%$ patients showed stable response and progressive disease respectively. In multiple fraction group complete response rate and partial response rate were $30 \%$ and $46.7 \%$ respectively whereas $23.3 \%$ patients showed stable response. $(\mathrm{p}=0.698)$. In study RTOG- 9714 complete and partial response rates were $15 \%$ and $50 \%$, respectively, in the singlefraction arm compared with $18 \%$ and $48 \%$, respectively, in the multiple-fractions arm $(p=0.6)$ [7]. In a Subset Analysis of Radiation Therapy Oncology Group Trial 97-14 by David D. Howell complete and partial response rates were $19 \%$ and $51 \%$, respectively in the single-fraction arm compared with $17 \%$ and $45 \%$ respectively in the multiple-fractions arm $(\mathrm{p}=0.59)^{[7]}$. Another study conducted by Akhil kapoor et al in north west India 
showed complete and partial response rates $22 \%$ and $36 \%$, respectively, in the single-fraction arm compared with $17 \%$ and $43 \%$, respectively, in the multiple-fractions $\operatorname{arm}^{[14]}$. These large multicentric randomized trials ${ }^{\text {[7], [14], [15] }}$ and two updated metaanalysis ${ }^{[12]}$ have found no significant difference in probability of achieving pain relief with different fractionation schedules of localized RT in painful uncomplicated bone metastases. Our findings are also in agreement, showing no significant difference in pain reliving efficacy with treatment either using $8 \mathrm{~Gy}$ in single fraction or $30 \mathrm{~Gy}$ in 10 fractions. Although this study revealed a higher rate of complete response in both arms than these previous trials, this difference may be accounted for smaller sample size and use of zoledronic acid in every 28 days in patients of both arms of our study.

In this study retreatment rate was $10 \%$ and $3.3 \%$ in single fraction and multiple fraction group respectively which is not significant $(p=0.3)$. In RTOG 9714 trial retreatment rates were $18 \%$ and $9 \%$ in single fraction and 10 fraction $\operatorname{arm}(\mathrm{p}<0.001)$ [7]. The meta-analysis by Chow et al reported retreatment rate of $20 \%$ and $8 \%$ in single fraction and multiple fraction groups $(\mathrm{p}<0.00001)^{[12]}$. This difference can be accounted by smaller sample size and short duration of follow-up in our study.

In this study treatment response had assessed by brief pain inventory. Mean score for all scores of brief pain inventory showed a downward trend throughout treatment although fall was less steep after 1 st or 2 nd month. Mean pain scores started to increase after 4th or 5th month in both arms. Statistical analysis revealed no significant difference between single fraction and multiple fraction arms in mean scores of brief pain inventory during treatment as well as during follow-up.

In our study most common toxicity was anorexia followed by anemia, nausea, vomiting, diarrhoea, leucopenia and thrombocytopenia. Grade 1 toxicity was $20.4 \%$ (18.5\% vs $22.9 \%$ ), grade 2 toxicity was $27.8 \%(26.2 \%$ vs $29.5 \%)$ and grade 3 toxicity was $8.8 \%(9.0 \%$ vs $8.5 \%)$. A greater incidence of toxicities were noted in multiple fraction arm, although this difference was statistically not significant $(p>0.05)$. The higher grades of toxicities were reported in patients receiving palliative chemotherapy during follow-up. No grade 4 toxicity was experienced by patients during study. No incidence of spinal cord myelopathy or pathological fracture was noted during study period. These toxicities were well manageable by either hospitalization or OPD basis. RTOG 9714 trial ${ }^{[7]}$ reported that more patients had acute grades 2-4 toxicities in multiple fraction arm (17\%) than in single fraction arm (10\%), this difference was significant $(\mathrm{p}=0.002)$. This difference can be accounted due to palliative chemotherapy or hormonal therapy in $60 \%$ patients during follow-up period in our study.

The use of single fraction radiotherapy in our trial saved on average additional 14 days of patients and their caregivers to complete their treatment. It saved direct and indirect costs of additional leave from work, travel, lodging and childcare; and work of healthcare providers and radiation therapists. The use of single fraction radiotherapy also reduced use of telecobalt machine.

\section{Conclusion}

With this study we concluded that $8 \mathrm{~Gy}$ in single fraction is as effective as $30 \mathrm{~Gy}$ in 10 fractions for palliation of bone metastases with fewer and manageable side effects. This short course radiation therapy is feasible for patients, caregivers, healthcare providers and radiation therapists. It also reduces excess burden of telecobalt machines especially in developing countries where enough radiation machines are already lacking.

\section{Conflict of interest}

We certify that there is no conflict of interest with any financial organization regarding the material discussed in the manuscript.

\section{Reference}

1. Ratanatharathorn V, Powers WE, Moss WT, et al. Bone metastasis: review and critical analysis of random allocation trials of local 
field treatment. Int J Radiat Oncol Biol Phys 1999;44:1-18.

2. Smith HS. Painful osseous metastases. Pain physician 2011;14:E373-E405.

3. Mandeep S Virk. Jay R Lieberman., Tumor metastasis to bone, Arthritis Research \& Therapy 2007, 9(Suppl 1):S5

4. Coleman RE, Clinical Features of Metastatic Bone Disease and Risk of Skeletal Morbidity, Clin Cancer Res. 2006 Oct $15 ; 12: 6243 \mathrm{~s}-6249 \mathrm{~s}$

5. Patrick W. Mantyh, Bone Cancer Pain: From Mechanism to Therapy, Curr Opin Support Palliat Care. 2014 June ; 8(2): 8390

6. William F. Hartsell and Santosh Yajnik., Palliation of Bone Metastases. In; Perez and Brady's principles and practice of Radiation oncology, Halperin E.C., Wazer D.E., Perez C.A., and Brady L.W., 6th edition, 2013. pp. $1778-1790$

7. Hartsell WF, Scott CB, Bruner DW, et al. Randomized trial of short- versus longcourse radiotherapy for palliation of painful bone metastases. $\mathrm{J}$ Natl Cancer Inst 2005;97:798-804.

8. Coleman RE. Metastatic bone disease: clinical features, pathophysiology and treatment strategies. Cancer Treat Rev 2001; 27:165-76

9. Body JJ; Metastatic bone disease: clinical and therapeutic aspects; Bone. 1992;13 Suppl 1:S57-62

10. Steenland E, Leer J, van Houwelingen $\mathrm{H}$, et al. The effect of a single fraction compared to multiple fractions on painful bone metastases: a global analysis of the Dutch Bone Metastases Study. Radiother Oncol 1999;52:101-109.

11. J.R.Yarnold; Bone Pain Trial Working Party. 8 Gy single fraction radiotherapy for the treatment of metastatic skeletal pain: randomized comparison with multi-fraction schedule over 12 months of patient followup. Radiother Oncol 1999;52:111-121
12. Edward Chow, Joel A. Finkelstein, Arjun Sahgal, and Robert E. Coleman., Metastatic Cancer to the Bone.In Devita, Hellman, and Rosenberg's cancer: principles \& practice of oncology, Vincent T. DeVita, Jr., Theodore S. Lawrence, Steven A. Rosenberg ; 10th edition, 2015. pp. 1867.

13. Sze WM, Shelley MD et al.; Palliation of metastatic bone pain: single fraction versus multifraction radiotherapy- a systemic review of randomized trials; Clin Oncol( $\mathrm{R}$ Coll Radiol) 2003;15:345-52

14. Kapoor, et al. Comparison of Single versus Multiple Fractions for Palliative Treatment of Painful Bone Metastasis: First Study from North West India: Indian Journal of Palliative Care / Jan-Apr 2015 / Vol 21 / Issue 1: 45-48

15. David D. Howell, MD et.al, Single-Fraction Radiotherapy Versus Multifraction Radiotherapy for Palliation of Painful Vertebral Bone Metastases-Equivalent Efficacy, Less Toxicity, More Convenient A Subset Analysis of Radiation Therapy Oncology Group Trial 97-14: Cancer. 2013 Feb 15;119(4):888-96. doi: 10.1002/cncr.27616. 